\title{
GLOBAL ATM RECONCILIATION ERROR CODES MAPPING FOR ALL OEM MANUFACTURERS WITH COMMON CODES FOR RECTIFICATION AND RECONCILIATION
}

\author{
Lebbaeus Denis \\ Research Scholar, Bharath Institute of Higher Education and Research (BIHER), \\ Chennai, India

\section{Dr. T. Krishna Kumar} \\ Assistant Professor, Department of Computer Science and Engineering, \\ Bharath Institute of Higher Education and Research (BIHER), Chennai, India

\section{Dr. Karthikeyan} \\ Professor and Principal, Department of Computer Science and Engineering, \\ Tamilnadu College Of Engineering, Coimbatore, India
}

\section{Dr. S. Sasipriya}

Professor, Department of Electronics and Communication Engineering, Sri Krishna College of Engineering and Technology, Coimbatore, India

\begin{abstract}
The Automated Teller Machine has transformed into an imperative bit of our general public. Utilizing the ATM anyway can frequently be a baffling encounter because of inclined glitches that happens in the machine. ATM makers have exhibited a few diverse mistake codes which starting at yet have not increased standard acknowledgment. This paper examines the different error codes thrown by various ATM machines produced by different manufacturers can be given a common code for very similar malfunctions made by the machine. Thereby to justify these common codes could gain world wide acceptance with the usage of the machines.
\end{abstract}

Keywords: ATM, OEM, Automated Teller Machine

Cite this Article: Lebbaeus Denis, Dr. T. Krishna Kumar, Dr. Karthikeyan, Dr. S. Sasipriya, Global ATM Reconciliation Error Codes Mapping for all OEM Manufacturers with Common Codes for Rectification and Reconciliation, International Journal of Advanced Research in Engineering and Technology (IJARET), 11 (1), 2020, pp 52-60.

http://iaeme.com/Home/issue/IJARET?Volume=11\&Issue $=1$ 


\section{INTRODUCTION}

ATM speaks to; Automated Teller Machine. It is furthermore implied as a coins device, a cash allocator and 'the outlet inside the divider' amongst diverse names. The ATM is an digital automatic media interchanges contraption that grants coins associated foundations (as an example bank or constructing society) customers to honestly use a secured gadget for correspondence to get to their budgetary adjusts. The ATM is a self-organisation banking terminal that recognizes stores and allots cash. Most ATM's moreover allowed customers to complete other budgetary trades (for example check balance). ATM's are incited by means of embeddings a financial institution card (cash or MasterCard) into the cardboard in line with purchaser establishing. The card will include the consumer's report quantity and PIN (Personal Identification Number) at the playing cards attractive stripe. Right whilst a customer is endeavouring to drag lower back coins for example, the ATM calls up the banks PCs to check the equality, allots the cash and after that transmits a completed exchange examine.

\section{EXISTING SYSTEM}

\subsection{ATM Reconciliation}

ATM Reconciliation is the way toward distinguishing, exploring, and settling contrasts between ATM Journals, ATM Switch exchanges; Physical money balance in the ATM, these information's gets populated from interior frameworks and outer frameworks or sources. Controls include consistency checks or variety checks either inside a framework or between frameworks. Compromise and Controls consistently lead to an examination procedure, investigation of recognized contrasts, remedial activities and issue acceleration and together comprise center parts of every single budgetary activity.

\subsection{Need for Reconciliation}

Each time two frameworks (inner or outer) record the equivalent money related exchange in an alternate manner, a compromise procedure must be executed as a last check to guarantee worldwide consistency.

Compromise in this way shapes a key segment of an organization's inner control framework.

For a Bank/MSP/CRA compromise can be a perplexing, repetitive and incredibly tedious procedures as it includes numerous instruments over various business applications. Furthermore, the various information sources and information positions utilized both remotely and inside, are not generally standardized, bringing about the reception of a few compromise apparatuses.

Compromise strategy, by its very nature, prompts an absence of solidified perspectives and thusly a higher introduction to hazard. This makes a requirement for a forward-looking venture wide compromise framework that lessens operational hazard and encourages money liquidity the board.

The requirement for a proficient and compelling ATM compromise procedure to adapt to the developing interest for ATM systems and self-overhauled exchanges is a key to a hazard controlled activity.

Just undertaking wide compromise arrangements can cover the full extent of compromise at every ATM Level and over the different frameworks of the association. 


\subsection{Performance Requirements}

Error message have to be shown in any occasion 6 seconds.

- If there may be no reaction from the Treasury PC following a solicitation inside mins, the card must dismiss with a mistake message.

- The ATM allots cash if and simply if the withdrawal from the file is looked after.

- Each Treasury need to system exchanges from some ATMs simultaneously.

- Cash collection time from the distributor need to be modified according with 30 seconds.

- The ATM device will complete the purchaser sign-on approach in below five seconds.

- The ATM gadget will understand the development kind preference in under 2 seconds.

- The ATM machine will apprehend the record decision in underneath 2 seconds

\subsection{Functional Requirements}

- The ATM framework should give get admission to to an authorized purchaser.

- The ATM framework need to well known consumer asks for and supply complaint.

- The ATM framework have to determine ATM reactions to inputs were given.

- The ATM framework ought to talk with the Treasury PC.

- The ATM framework have to have a Language dedication alternative.

- The framework ought to request account type.

- The framework need to check for printing receipt.

- The framework need to request upload up to be pulled lower back at the off chance that it's far withdrawal.

- Dispense money and fee the sum if there may be sufficient report stability.

- If there is not enough parity blunder message should be shown.

- If it's miles stability enquiry, a printed receipt have to take delivery of.

- If it's miles small scale clarification call for, a printed receipt need to accept.

- If ATM is out of request or inadequate cash in the tapes a blunder message need to take delivery of.

- The ATM shape will offer functions to re-supply and backing. 
Global ATM Reconciliation Error Codes Mapping for all OEM Manufacturers with Common Codes for Rectification and Reconciliation

\subsection{Reconciliation Overall Process}

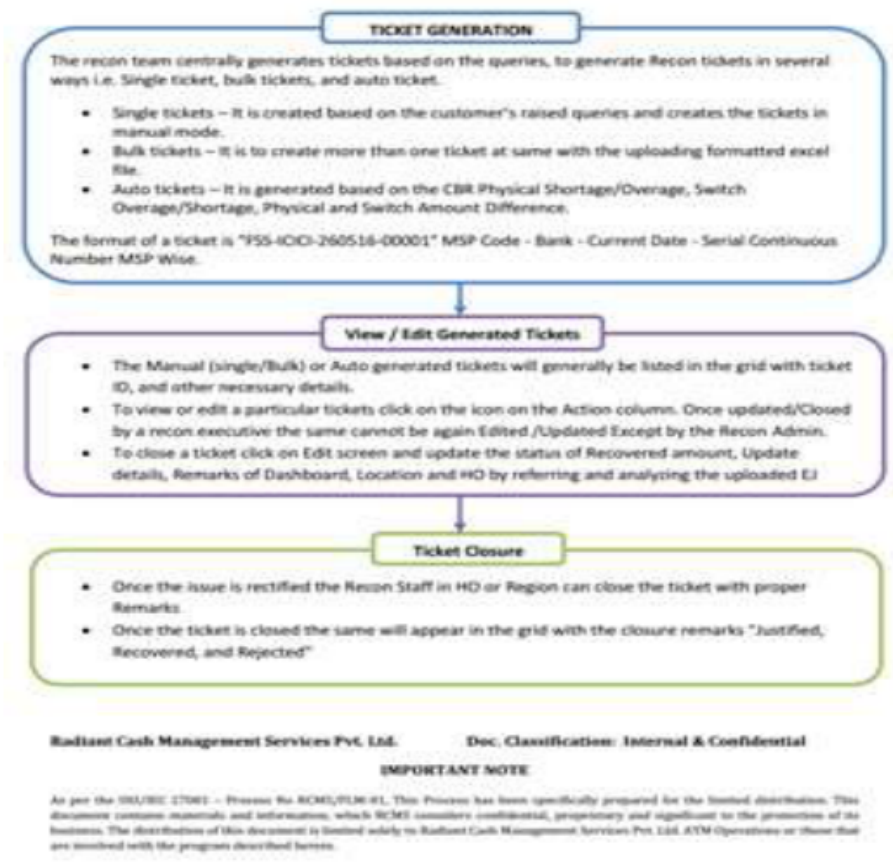

Figure 1 Single Ticket Generation

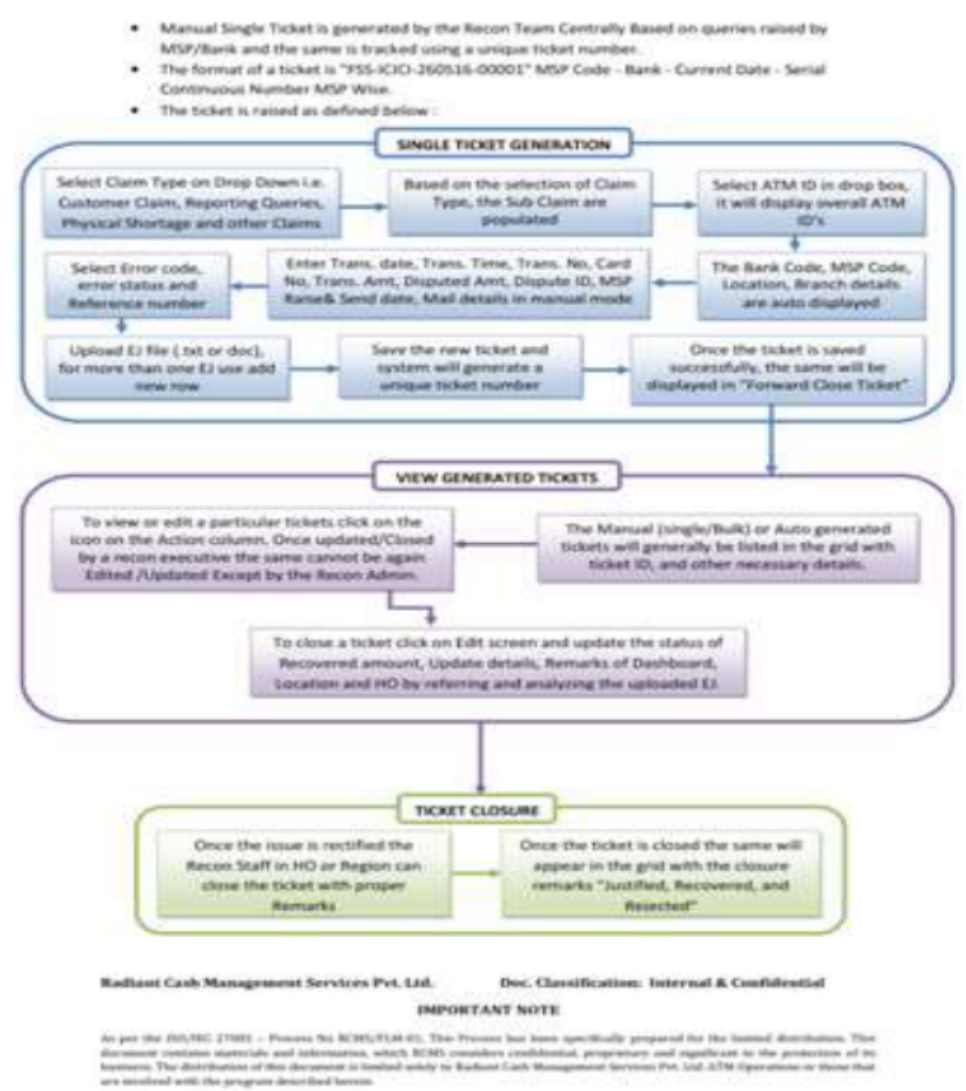

Figure 2 Bulk Ticket Generation - Process Flow 
Lebbaeus Denis, Dr. T. Krishna Kumar, Dr. Karthikeyan, Dr. S. Sasipriya

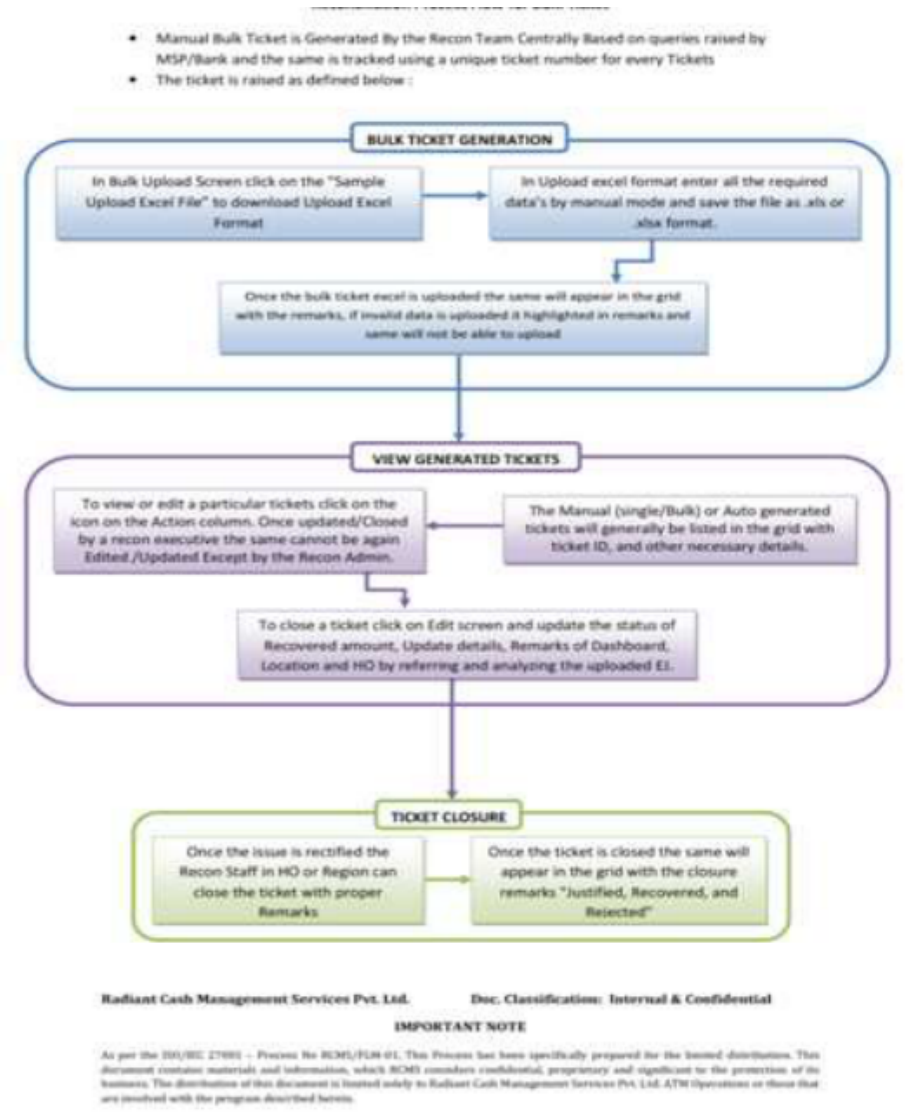

Figure 3 Process Flow

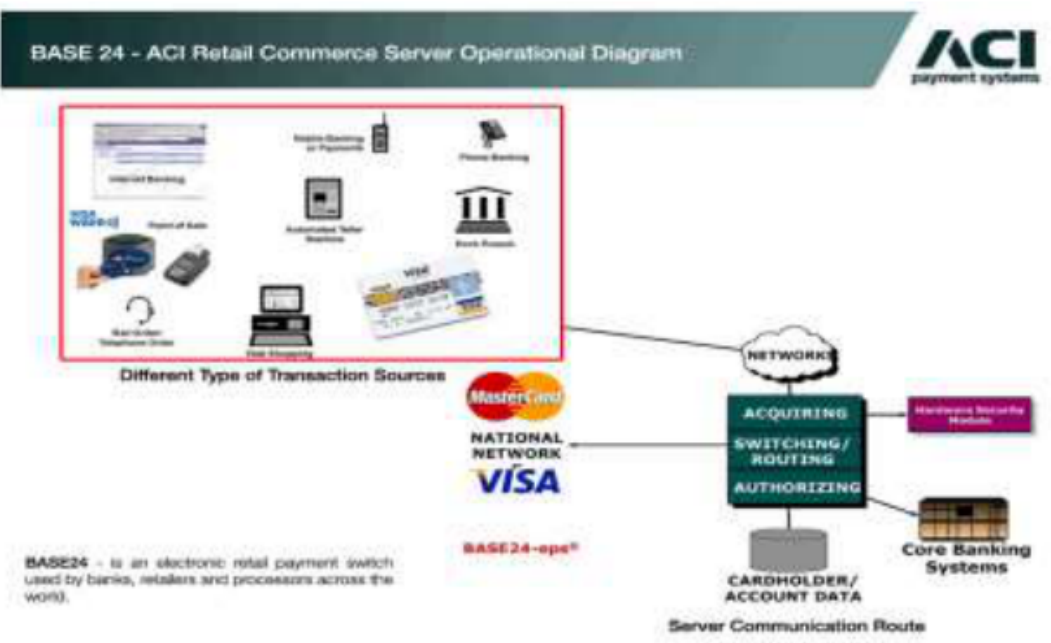

Figure 4 Base 24 - Payment Switch

An ATM switch is like a network switch which associates gadgets and procedures and passes data back and forth from the associated gadgets. ATMs were initially independent devices since information on monetary adjusts themselves were circled across over branches. Later when all record information got united records could be revived steady. In the mid-90s some open part banks got the splendid idea that they could share their framework. This necessary a central change to pass information between frameworks. In coming about quite a while there was a couple of such shut frameworks. Around 2004, the RBI's assistant IDRBT made a National Finance Switch to relate all ATMs. The action of the switch was passed on 
the National Payments Corporation of India in 2007. The NPCI found that the NFS could be used for progressing resource move additionally and the IMPS were made riding on the NFS. The NPCI's latest movement the Unified Payments Network which licenses portions from any versatile financial application to some other application rides on the IMPS.

\subsection{Benefits}

- Experts in the business and offers their involvement in the representative

- Well known bank 374 branch workplaces.

- More than 2,800 ATM machines

- Correspondent budgetary relationship with 700 remote banks all through the world.

- Strong execution where it was recorded second greatest in Malaysia Stock Exchange and Bursa Malaysia

\section{IMPLEMENTATION AND SECURITY ANALYSIS}

\subsection{Tranax Error Codes Diebold or Triton}

\begin{tabular}{|c|c|c|}
\hline $\begin{array}{l}\text { ERROR } \\
\text { CODE }\end{array}$ & $\begin{array}{c}\text { ERROR } \\
\text { DESCRIPTION }\end{array}$ & SOLUTION \\
\hline 0 & Normal Status & Normal Status \\
\hline 400 & $\begin{array}{l}\text { Dim light sensor test } \\
\text { error(CS11A, CS11B, } \\
\text { CS4) during instating. }\end{array}$ & $\begin{array}{l}\text { 1. Check if every sensor is mounted. } 2 \text {. In the } \\
\text { event that blunder happens while checking } \\
\text { CS11A link activity, supplant a sensor. } 3 \text {. On the } \\
\text { off chance that mistake happens while checking } \\
\text { CS11B link activity, supplant a sensor. } 4 \text {. In the } \\
\text { event that blunder happens while checking CS4 } \\
\text { link activity, supplant a sensor. }\end{array}$ \\
\hline 4000 & $\begin{array}{l}\text { Blunder of being } \\
\text { evacuated second tape } \\
\text { before independent } \\
\text { dismissal }\end{array}$ & \\
\hline 4004 & $\begin{array}{l}\text { Mistake of being } \\
\text { evacuated second tape } \\
\text { before independent } \\
\text { dismissal }\end{array}$ & $\begin{array}{l}\text { 1. Set tape } \# 2 \text { accurately } 2 \text {. Check the catcher } \\
\text { inside tape } \# 2 \text { control }\end{array}$ \\
\hline 5300 & No Savings Account & \\
\hline 10301 & DEV_PIN & \\
\hline 20001 & $\begin{array}{l}\text { Incapable to stack a } \\
\text { tape. }\end{array}$ & $\begin{array}{l}\text { Expelled and supplant tape Check the } \\
\text { miniaturized scale switch situated within left mass } \\
\text { of the gadget. }\end{array}$ \\
\hline 20002 & Low cash. & $\begin{array}{l}\text { Renew the money if utilizing under } 75 \text { bills, } \\
\text { debilitate the ÒLow Cash Warningó in the } \\
\text { Transaction Setup Menu. }\end{array}$ \\
\hline 20003 & Reject Bin full. & $\begin{array}{l}\text { Void the Reject Bin-If the container is unfilled, do } \\
\text { a Day Total and afterward a Cassette Total-If than } \\
\text { doesnõt help, check AP, BIOS and CDU ROM } \\
\text { adaptations. }\end{array}$ \\
\hline
\end{tabular}




\subsection{Attacks in Automated Teller Machine}

ATM dangers can be segmented into three sorts of ambushes: card and money misrepresentation, insightful assaults and physical assaults

\section{Card and Cash Fraud}

Card and money extortion includes both direct assaults to take money from the ATM and aberrant assaults to take a purchaser's character (as shopper card information and PIN burglary). The plan of roundabout assaults is to falsely utilize the buyer information to make fake cards and get cash from the shopper's record through fake reclamation.

\section{Skimming Attack}

Card and money extortion includes both direct assaults to take money from the ATM and roundabout assaults to take a customer's personality (as purchaser card information and PIN burglary). The purpose of circuitous assaults is to deceitfully utilize the buyer information to make fake cards and acquire cash from the shopper's record through fake reclamation.

\section{Card Trapping and Fishing}

Card getting is driven by setting a device over or inside the card per client opening to get the customer's card. These can be devices, for instance, plates over the card per client, pitiful metallic strips covered in a plastic clear film, wires, tests and catches. These gadgets are proposed to shield the card from being returned to the buyer toward the piece of the plan

\section{Card and currency Logical/data Attacks}

It remembers assault for ATM's product, working framework and correspondence system and frameworks. Principle target is to acquaint infections proposed with abuse an ATM's working framework for the most part employment of programmers who introduce malware to damage the secrecy, honesty or legitimacy of exchange related information.

\section{Physical Attacks}

It consolidates getting cash by physically hurting the ATM. It incorporates any section or part of the ATM.

\subsection{OUTCOMES}

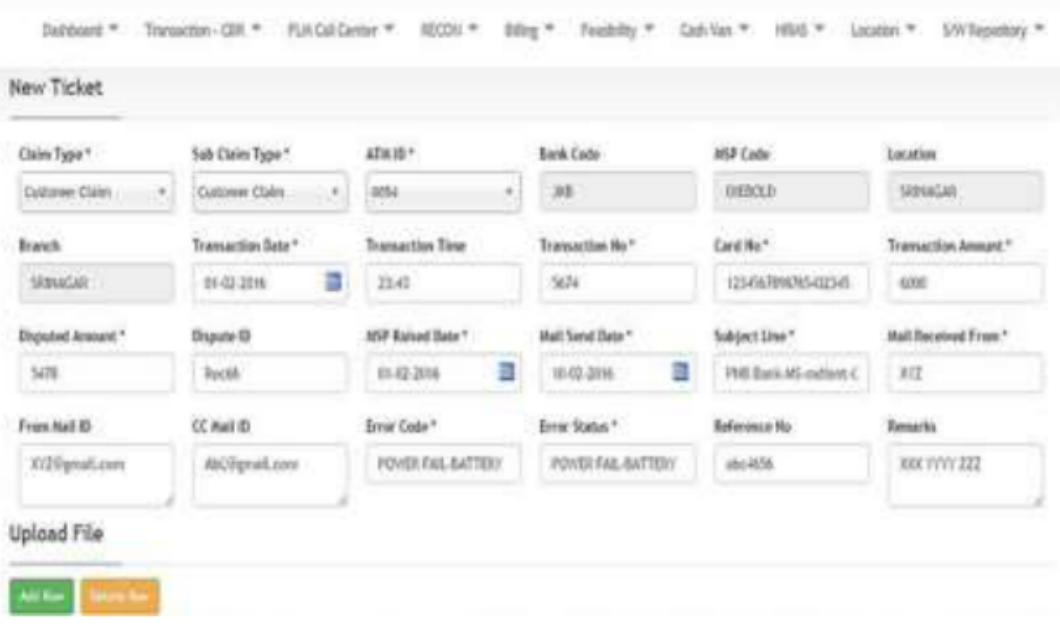

Figure 5 Reconciliation process 
Global ATM Reconciliation Error Codes Mapping for all OEM Manufacturers with Common Codes for Rectification and Reconciliation

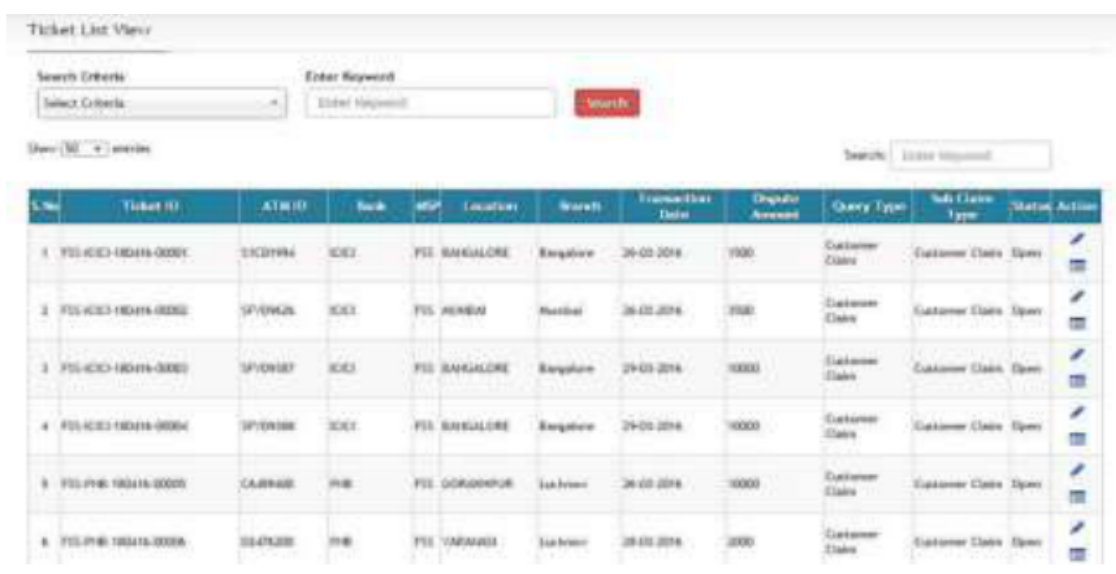

Figure 6 Recon ticket

The example above is for illustrative purpose only and is not real data

There are four types of claimtype: Customerclaim, ReportingQuery, PhysicalShortage, Others, all these are interbank and MSP based with CRA and sans geography and we address them based on error codes and ticket generation.

\begin{tabular}{|c|c|c|}
\hline $\begin{array}{l}\text { Customer } \\
\text { Claim }\end{array}$ & Error Code & Error Description \\
\hline 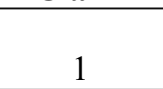 & Application Started & $\begin{array}{l}\text { Counter gone up, ATM Working Fine } \\
\text { Application Started }\end{array}$ \\
\hline 2 & Application Started & $\begin{array}{l}\text { Counter gone up, ATM stopped } \\
\text { working Application Started }\end{array}$ \\
\hline 3 & Application Started & $\begin{array}{l}\text { Counters not gone up, ATM working } \\
\text { fine Application Started }\end{array}$ \\
\hline 4 & Cash Retracted & $\begin{array}{l}\text { ATM working fine Cash presented, } \\
\text { Not Taken }\end{array}$ \\
\hline 5 & Cash Retracted & $\begin{array}{l}\text { ATM working fine CASH } \\
\text { RETRACTED }\end{array}$ \\
\hline 6 & Communication Error & $\begin{array}{l}\text { ATM working fine Communication } \\
\text { Error }\end{array}$ \\
\hline 7 & Communication Error & $\begin{array}{l}\text { Machine stop dispensing } \\
\text { Communication Error }\end{array}$ \\
\hline 8 & CPTE & Retraction Disabled ATM CPTE \\
\hline 9 & Customer Timeout & $\begin{array}{l}\text { ATM Working Fine Customer } \\
\text { Timeout }\end{array}$ \\
\hline 10 & Power Fail & ATM Working Fine Power fail \\
\hline 11 & DR01:23:00:30/DR01:3F:00:40 & $\begin{array}{l}\text { Followed by } \\
\text { DR01:23:00:30/DR01:3F:00:40 } \\
\text { Successful }\end{array}$ \\
\hline 12 & Successful Trxn & ATM Working Fine Successful \\
\hline 13 & DI01:3F:39:34 & $\begin{array}{l}\text { Followed by DI01:3F:39:34 } \\
\text { Successful }\end{array}$ \\
\hline 14 & Decline Transaction & Followed by Declined Successful \\
\hline 15 & $\mathrm{E} * 2$ & Followed by E*2 Successful \\
\hline 16 & Successful Trxn & Machine stop dispensing Successful \\
\hline 17 & Successful Trxn & Followed by full reversal Successful \\
\hline 18 & DI01:3B:33:33/DI01:3E:33:33 & $\begin{array}{l}\text { DI01:3B:33:33/DI01:3E:33:33 } \\
\text { Machine stop Successful }\end{array}$ \\
\hline 19 & DI01:3B:33:33/DI01:3E:33:33 & $\begin{array}{l}\text { DI01:3B:33:33/DI01:3E:33:33 ATM } \\
\text { Working Successful }\end{array}$ \\
\hline 20 & $\mathrm{E}^{*} 0$ & E*0 ATM Working Fine Successful \\
\hline
\end{tabular}




\section{CONCLUSION}

In this paper, we conclude that all the similar error codes that are generated by ATM machines can be categorized under some standard common codes that would be used widely. The Key benefits of this theory is to minimize the amount of duplicate codes that are produced by various ATM manufactures by sharing a unique common code so that it gains recognition equivalent to existing numerous duplicate codes. This tends to result in a better organization of codes providing simpler compilation that can even be interpreted by a common man.

\section{REFERENCES}

[1] Gupta, Manav. "Dynamic Widget Generator Apparatuses, Methods and Systems." 2018.

[2] Elsden, et.al. "Making sense of Blockchain Applications: A Typology for HCI." 2018.

[3] Davenport, et.al. "Artificial Intelligence for the Real World (2018).

[4] Laracey, Kevin. "Mobile Phone ATM Processing Methods and Systems 2018.

[5] Wei, Jin, et.al.. "Actuator and Sensor Faults Estimation for Discrete-Time Descriptor Linear Parameter-Varying Systems in Finite Frequency Domain." (2018).

[6] Li, Gang et.al. "Data-Driven Root Cause Diagnosis of Faults in Process Industries (2016)

[7] Subramaniam, et.al. "Fault Tolerant Economic Model Predictive Control for Energy Efficiency in a Multi-Zone Building." 2018

[8] Kobres, et.al. "Techniques for Automated Teller Machine (ATM) Transactions2018

[9] Wu, et.al. "Financial Transaction System, Automated Teller Machine (ATM), and method for Operating an ATM 2011.

[10] Chanajitt, et.al. "Forensic Analysis and Security Assessment of Android M-Banking Apps 2018 .

[11] Ferrer, et.al.. "The blockchain: A New Framework for Robotic Swarm Systems

[12] Lindsay, Jeffrey Dean. "Security systems for protecting an asset." 2018

[13] Banerjee, et.al. "A Blockchain Future for Internet of Things Security: 2018.

[14] Sant'Anselmo, et.al. "Digital Signatory and Time Stamping Notary Service for Documents and Objects." 2018.

[15] Moritz, et.al. "Behavioral Profiling Method and System to authenticate a user." 2018.

[16] Guntu. Nooka Raj and Dr. B. Prabhakara Rao, Multiuser Detection Using Neural Network for FD-MC-CDMA System in Frequency Selective Fading Channels. International Journal of Electronics and Communication Engineering and Technology, 9(6), 2018, pp. 9-20

[17] A. Anitha, M. Varalakhshmi, A. Mary Mekala, Subashanthini and M. Thilagavathy, Secured Cloud Banking Transactions using Two-Way Verification Process, International Journal of Civil Engineering and Technology, 9(1), 2018, pp. 531-540

[18] Shailesh N. Sisat, Duplicate and Fake Currency Note Tracking in Automated Teller Machine (ATM), International Journal of Electronics and Communication Engineering \& Technology (IJECET), 5(1), 2014, pp. 11-15 